NBSIR 75-768

\title{
Reevaluation of the Densities of the Four NBS Silicon Crystal Standards
}

H. A. Bowman

R. M. Schoonover

C. L. Carroll

Institute for Basic Standards

National Bureau of Standards

Washington, D. C. 20234

August 1975

Final

Prepared for

Mechanics Division

Institute for Basic Standards

Washington, D. C. 20234 
NBSIR 75-768

REEVALUATION OF THE DENSITIES OF

THE FOUR NBS SILICON CRYSTAL STANDARDS
H. A. Bowman
R. M. Schoonover
C. L. Carroll

Institute for Basic Standards

National Bureau of Standards

Washington, D. C. 20234

August 1975

Final

Prepared for

Mechanics Division

Institute for Basic Standards

Washington, D. C. 20234

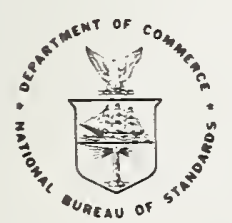

U.S. DEPARTMENT OF COMMERCE, Rogers C.B. Morton, Secretary James A. Baker, III, Under Secretary

Dr. Betsy Ancker-Johnson, Assistant Secretary for Science and Technology

NATIONAL BUREAU OF STANDARDS, Ernest Ambler, Acting Director 

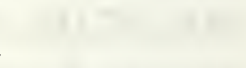


\section{Reevaluation of the Densities of the Four NBS Silicon Crystal Standards}

by

H.A. Bowman, R.M. Schoonover, and C.L. Carroll

$\underline{\text { ABSTRACT }}$

There were a few features of our recently completed density standard experiment which were based upon ideas which, we believe, should be changed. This report lists these changes and their justification. The result is to increase the assumed values of the densities of the crystals by about $1.88 \mathrm{ppm}$. The new assumed values are

$$
\begin{aligned}
& x_{2}=2.3291289 \mathrm{~g} / \mathrm{cm}^{3} \\
& x_{3}=2.3291253 \mathrm{~g} / \mathrm{cm}^{3} \\
& x_{4}=2.3291228 \mathrm{~g} / \mathrm{cm}^{3} \\
& x_{5}=2.3291226 \mathrm{~g} / \mathrm{cm}^{3}
\end{aligned}
$$

Additionally, we now believe that the densities of the crystals are stable, and not appreciably changing due to oxidation -- a point left unresolved in our published report.

Key Words: Density standard; phase shift; silicon 
Reevaluation of the Densities of the Four NBS Silicon Crystal Standards by

H.A. Bowman, R.M. Schoonover, and C.L. Carroll

\section{Introduction}

From 1969 to 1974 the NBS Mass and Volume Section developed the apparatus and procedures necessary to the accomplishment of the following rather difficult tasks:

a. Measurement of the geometry of six steel balls in terms of the universally accepted wavelength displacement scale. This instrument was described by Saunders, NBS [1].*

b. Calculation of ball volumes from these geometric measurements based upon the theory of Johnson, NBS [2].

c. Derivation of the volumes of four silicon crystals from the previously determined ball volumes. This required the development of a hydrostatic volume comparator which would provide the unknown volume of an object as a fraction of the known volume of a standard. This work, in which the balls were standards and the crystals were unknowns is described in [3].

d. Calculation of the crystal densities from a mass measurement and the previously derived crystal volumes. At this point in time (late 1973) NBS abandoned the use of pure water as a density standard and commenced referring all density measurements to the silicon crystals. While the balls could have served equally well as density standards in future work, for practical reasons silicon crystals were chosen for this task. The apparatus and procedures for this and future routine density work, and reasons for discarding water as a standard, are discussed in [4].

This article results from a very critical examination of all of the above four tasks in which apparatus, procedures, data reduction techniques all came under very close scrutiny. As is always the case, there are several features which we would improve if the project were just beginning.

* Numbers in brackets refer to simitarly numbered references at the end of this paper. 
a. With more forethought in the design of the thermal system controlling the ball interferometer, we would have obtained very much better temperature measurements.

b. We wish we had employed five rather than four 200 gram silicon crystals (summation mass $=1$ kilogram) which would have reduced the uncertainties in the crystal masses. This was our original intent, but, as explained in the caption to figure 6 of our final report [3], one of them was accidentally destroyed.

c. We wish we had employed balls of 2.465 inches in diameter (mass $=1$ kilogram) but we were dazzled by the low cost of the off-the-shelf $2 \frac{1}{2}$ inch size.

Our re-examination has disclosed four numerical errors -- either blunders or misprints -- of no overall significance. Other features of the experiment which have received additional attention include the algorithm used in the reduction of the photographically obtained interferograms during the etalon length studies, the cleaning procedure applied to the balls prior to the interferometric diameter determinations, and the growth of oxide films on the surfaces of the silicon crystals.

Additionally we discuss some features of the experiment which should have been included in our final report such as the initial four-color interferometry on the etalon length and the basis of our phase shift assumptions upon which our data reduction formulas were based.

\section{Phase Shift Correction}

No other topic created as much discussion during the experiment as our assumption regarding the algebraic sign of the phase shift correction. In our report we stated that the phase of light reflected from a metal surface is retarded with respect to that which is reflected from an equidistant quartz surface. Our formulas for the reduction of interferometric data on ball diameters were based upon this assumption. Our assumption was formed after a careful reading of the very concise statement of Englehardt [5] who said that ". . . gage blocks measured by light waves seem to be too short.... when wrung on an insulating plate ... " At a meeting of our senior division staff members in the division conference room, this statement was suspected of being in disagreement with the (then) newly published report of Bennet, [6]. Although this is outside of our expertise, we can find no disagreement. She states that the 
optical path is shorter than the geometric path which is equivalent to having the reflection occur at a fictional surface in front of the real surface. Her measured phase change from a metallic surface (aluminum film) is $157^{\circ}$. In other words, light appears to be reflected from a surface $180 \% / 2$ in front of a quartz surface but only $157 \% / 2$ in front of a metallic surface. Candler [7] discussing this particular point says ". . . When light is reflected at a glass surface, the phase changes by $\pi$ which means that the light appears to be reflected from the geometric surface. When light is reflected in air at a metallic surface, an additional change of phase occurs; in effect the light then appears to penetrate the metal, and the reflecting surface is displaced from the geometric surface." Candler is obviously discussing destructive interference when he states that light is reflected from the glass surface (zero order indicates zero distance). Bennett is interested in absolute phase shift under which circumstances the position of the apparent reflecting surface has great significance. On the other hand, since Englehardt and Candler refer to comparative experiments, it makes no difference where the apparent reflecting planes are located (in front of or behind) the real surface.

The significant point is that all three authors agree that the reflection from a quartz surface appears to come from a plane CLOSER TO the source than the reflection from an equidistant metal surface. This is the sense of our stated assumption and the resulting formulas. It has been suggested that a proper solution of the Fresnel equations would eliminate any doubt on this point. If such a solution is presented to us, we will quickly make an appropriate adjustment to our data.

Metrologists sometimes define the phase shift correction as the difference between optical and mechanical measurements, in which case they assume a multi-component phenomena. One of these components, described by Strang [8] results from hills and valleys on the reflecting surface, the effect of which is a fringe broadening and a shift of the reflecting surface away from the source. Although we did have measurements on our ball surfaces, appendix 1 , we did not apply such a correction because we assumed that the hydrostatic liquid used in the volumetric transfer tests would fill these hills and valleys, in which case the hydrostatic surface was equal to the reflection surface and (hence) no correction is called for.

\section{Average Etalon Length from 4-Color Interferometry}

The first interferometric measurements of the length of the etalon employed the four bright mercury lines. Wavelengths in air were calculated by Edlen's formulas [9] from tabulated values of vacuum wavelength and observed values of air temperature, barometric pressure and relative humidity. Some selected data are given below. 


\begin{tabular}{|c|c|c|c|}
\hline Line & $\begin{array}{l}\text { Wavelength } \\
\text { in Air } \\
\end{array}$ & $\begin{array}{l}\text { Test } \\
\text { Temp }\end{array}$ & $\begin{array}{l}\text { Observed } \\
\text { Fraction } \\
\end{array}$ \\
\hline $\begin{array}{l}\text { Blue } \\
\text { Green } \\
\text { Yellow - } 1 \\
\text { Yellow - } 2\end{array}$ & 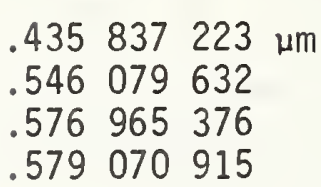 & $\begin{array}{l}19.91^{\circ} \mathrm{C} \\
19.92 \\
19.90 \\
19.99\end{array}$ & $\begin{array}{l}.683 \\
.057 \\
.792 \\
.362\end{array}$ \\
\hline
\end{tabular}

The computer was set up to assume a value of etalon length and coefficient of expansion at $20^{\circ} \mathrm{C}$ and to calculate the fringe fraction which would have been observed had the assumed etalon length been correct. The calculated fraction was subtracted from the fraction actually observed. If the difference between the observed and calculated fraction was less than 0.05 for all four colors, the computer printed out the assumed etalon length and a11 four differences.

We had a preliminary measurement of the etalon length based upon gage blocks and a mechanical comparator of $67471.4 \mu \mathrm{m}$. The computer was called on to scan possible etalon lengths at every $0.005 \mu \mathrm{m}$ increment between 67000 and $68000 \mu \mathrm{m}$ and to calculate fractions appropriate to the assumed lengths. The criterion for recognizing a correct solution was that the difference between observed and calculated fractions would not only pass through zero for all colors but all four algebraic signs would swing from $(-)$ to $(+)$. Over this entire $1000 \mu \mathrm{m}$ range, there was only one solution meeting the above criterion. The values are as follows:

Assumed Etalon Length at $20^{\circ} \mathrm{C}$

$67471.565 \mu \mathrm{m}$ 67471.570

\begin{tabular}{cccc} 
Blue & \multicolumn{2}{c}{ Calculated Minus Observed Fractions } \\
Green & Yellow-1 & Yellow-2 \\
\hline$(-) 7.96 \times 10^{-5}$ & $(-) 9.44 \times 10^{-3}$ & $(-) 1.64 \times 10^{-2}$ & $(-) 4.59 \times 10^{-3}$ \\
$(+) 2.92 \times 10^{-2}$ & $(+) 8.87 \times 10^{-3}$ & $(+) 9.71 \times 10^{-4}$ & $(+) 1.27 \times 10^{-2}$
\end{tabular}

From the above data and several other sets of less internal consistency, we concluded that the etalon length lay between 67471.565 and $67471.570 \mu \mathrm{m}$. As explained in Saunders' report, this four color work was performed only to provide us with a reliable estimate of the integral order of interference for later etalon length measurements using a single laser line. The later laser work was necessary because the four color work provided us with the length averaged over the entire aperture of the etalon. In use, the working aperture was only a few square millimeters and we had no justification for assuming these two lengths would be equal. Additionally, the temperature measurements were unreliable during the four color work because the configuration of the optical system employed during this work required that the etalon be removed from its thermostat housing during measurements . 


\section{Fringe Pattern Analysis}

When measuring the etalon length, either by four color or single color interferometry, the etalon functions as a Fabry-Perot interferometer. When the calibrated etalon is used to measure ball diameters, it acts as a Newton's Rings generator. Although the pattern of interference is superficially the same in each case (concentric rings about a bull's-eye) there is a significant difference. In the Fabry-Perot situation, the order of interference increases with rings of decreasing diameters while in the case of Newton's Rings, the order decreases with decreasing dian:eters [7].

Our interference patterns were photographed on $35 \mathrm{~mm} f i 7 \mathrm{~m}$, and measurements were made directly upon the negatives. Under these circumstances, black (or opaque) rings were areas of constructive interference while transparent rings were of destructive interference. Measurements were made using a traveling microscope, with the film positioned so that the cross hairs in the eyepiece passed through the center of the bull's-eye. Position data indicated on the dials of the microscope were recorded whenever the cross hairs lay on a boundary between a black and a transparent ring.

This setup provided us with the inside and outside diameters, $d_{i}$ and $d_{0}$, of the first few rings surrounding the bull's-eye. From these measurements, we were able to calculate a number proportional to the area enclosed by a circle at some average position within the ring

$$
A=\frac{d_{i}^{2}+d_{0}^{2}}{2}
$$

The rings were numbered $N=1, N=2$, etc. and the data points ( $A_{1}$, $\left.N_{1}\right),\left(A_{2}, N_{2}\right),\left(A_{3}, N_{3}\right) \ldots$ were fitted to

$$
N=X+Y A+Z A^{2}
$$

which provided us with a value of $N$ when the area, $A$, was zero. We assumed that the fractional portion of $X$ was the desired fringe fraction. In this work we used the first five rings and the reduced data is given in table 3 of our final report.

The geometry of our system was such that we should have obtained the same fractional order of interference regardless of the direction of the light through the etalon -- that is, left-toright or right-to-left. In most of the etalon measurements presented in table 3 of the final report [3], four fractions are 
shown, two in each direction. The final calculation of the etalon length is based upon the average value of these four fractions. The range over which these four fractions varied (within a single test) averaged 0.024 .

A slightly different technique was employed during reduction of the ball interferograms.

The fringe reduction formula, developed below, was worked out for us by D.P. Johnson, NBS. In this procedure, in which all fringes are assumed to have equal area, we confine our attention to the three opaque rings surrounding a transparent bull's-eye as shown in figure 1 or the three transparent rings surrounding an opaque bull's-eye. Twelve observations, $0_{1}$ to $0_{12}$ are made on the indicating dials of the traveling microscope when the reticle is positioned as indicated in the figure. From these twelve observations we can calculate numerical values of $Y$ which are proportional to the areas of the six circles which form. the inside and outside diameter of the three rings under examination.

$$
\begin{aligned}
& Y_{1}=\left(0_{7}-0_{6}\right)^{2} \\
& Y_{2}=\left(0_{8}-0_{5}\right)^{2} \\
& Y_{3}=\left(0_{9}-0_{4}\right)^{2} \\
& Y_{4}=\left(0_{10}-0_{3}\right)^{2} \\
& Y_{5}=\left(0_{11}-0_{2}\right)^{2} \\
& Y_{6}=\left(0_{12}-0_{1}\right)^{2}
\end{aligned}
$$

$A$ is defined as a number proportional to the area of a complete fringe, that is, a transparent ring plus an adjacent opaque ring. We have two estimates of the value of $A$, that is

$$
\begin{aligned}
& 2 A=Y_{6}-Y_{2} \\
& 2 A=Y_{5}-Y_{1} \\
& \hline 4 A=Y_{6}+Y_{5}-Y_{2}-Y_{1}
\end{aligned}
$$

Let $F$ be the number of fringes between the optical center of the intermediate second ring under observation, that is, the circle of complete constructive or destructive interference, and the center of the bull's-eye. Then FA is proportional to the area of the circle defining the optical center of the intermediate ring. This circle divides this intermediate ring into two nearly equal areas, WA. FA and WA are shown in the sketch. 
We may write and add together six observation equations as follows:

$$
\begin{aligned}
-W A-A+F A & =Y_{1} \\
+W A-A+F A & =Y_{2} \\
-W A+F A & =Y_{3} \\
+W A+F A & =Y_{4} \\
-W A+A+F A & =Y_{5} \\
+W A+A+F A & =Y_{6} \\
\hline 6 F A & =\left[Y_{1}+Y_{2}+Y_{3}+Y_{4}+Y_{5}+Y_{6}\right]
\end{aligned}
$$

From equations (1) and (2)

$$
F=\frac{F A}{A}=\frac{\frac{1}{6}\left[Y_{1}+Y_{2}+Y_{3}+Y_{4}+Y_{5}+Y_{6}\right]}{\frac{1}{4}\left[Y_{6}+Y_{5}-Y_{2}-Y_{1}\right]}
$$

The fractional component of $F$ is the desired fringe fraction or its complement depending upon whether constructive or destructive interference is of interest.

It was suggested that we would have been better advised to employ this same procedure in reducing etalon data. We were delighted to find that this suggestion resulted in a reduction in range of data by almost one-half. Use of the newly calculated fractions resulted in a measured value of etalon length shorter than the published value by about $0.0048 \mu \mathrm{m}$. This was probably due to systematic reading errors made during estimating diameters of the very thin outer rings which are not involved in Johnson's technique.

The recalculated etalon data is presented in table 1 which may be compared with table 3 in the published report.

\section{Ball Cleaning}

We had three sources of information on the approximate diameters of our balls -. a necessary prerequisite to monochromatic interferometry. These sources were:

a. Measurements made by the manufacturer by comparing the balls to standard balls of "known" diameter.

b. Measurements by the NBS Dimensional Metrology Laboratory by comparison with stacks of gage blocks between flat-faced probes. 
c. Measurements by our Gage Block Laboratory against different gage blocks, but in a mechanical comparator employing spherical probes. In this case, since lateral displacement of the ball from the measuring axis would result in a decrease in the indicated diameter, this measurement must be considered a "minimum" value -- that is, the ball may be larger than indicated but relatively less probably, smaller.

These three values, see figure 2, were in agreement to the extent that we had no worries about our ability to assume a proper value for the integral order of interference in later tests by the etalon interferometer.

Very early in the program, we realized that the ball diameters calculated from interferometric data varied systematically with the cleaning procedure applied to the balls prior to insertion in the interferometer. We made extensive tests on this phenomenon employing Balls A and B. Two methods of cleaning were examined:

A. CHEMICAL CLEANING. This procedure involved the following steps -- washing with a detergent followed by washing in acetone followed by rinsing in benzene followed by rinsing in methyl alcohol followed by wiping with a laboratory cleaning paper (Kimwipes). An alternative cleaning procedure involved all of the above steps except that a commercial gage block cleaner (Doall degreaser) was used instead of the acetone, benzene and methyl alcohol.

B. VAPOR DEGREASING. This process involved chemical cleaning by either of the above two procedures except that wiping was eliminated and instead the ball was immersed in a stainless steel vapor degreaser in which we boiled a commercial solvent (Dow Chemical Co. No. WR-5) which was especially developed to have only a few ppm of nonvolatile components. After about an hour's exposure to the hot vapor, the ball was removed from the apparatus. Due to its high temperature when first removed (about $130^{\circ} \mathrm{C}$ ) any residual liquid evaporated so that wiping the ball was unnecessary.

After cleaning (by either method) the worker always wore clean polyethylene gloves whenever the ball was handled. When inserting the ball in the interferometer, vacuum tweezers machined out of teflon were used. The diameters caiculated from interferometric data were always slightly larger when vapor degreasing preceded the tests than when chemical cleaning was used. This was true regardless of which method of chemical cleaning was employed. 
These interferometrically measured diameters are shown in table 2. It is clear that there is a systematic difference depending upon how the ball was cleaned prior to test. Inasmuch as the difference is so clearly systematic, we felt that we should not average all measurements together but should select one type of cleaning or the other. Inasmuch as the range of the diametric measurements is smaller when vapor degreasing is used, all future work on the balls followed vapor degreasing.

Since the publication of our report, we have had serious second thoughts regarding the wisdom of that decision. To investigate this phenomenon more completely, we obtained a group of 52100 steel gage blocks (the same alloy from which the balls were made). Two of the blocks were cleaned chemically and two by vapor degreasing.

These four blocks were turned over to Dr. John Yates and associates, NBS Surface Chemistry Section, who examined them by Auger Spectroscopy [12] to explore any surface film which might be associated with the cleaning procedure. He found no differences between the films on the two pairs of blocks except for weak zinc lines and some extraneous secondary electron emission from the chemically cleaned blocks. The zinc lines were believed to come from contamination due to the tissue paper used to wipe the balls following chemical cleaning. His conclusion was that no surface film was present which would account for the large measured diametric difference unless the film was volatized in the Auger spectrometer vacuum.

Our next thought was that the cleaning procedure altered the optical properties of the 52100 surfaces in a manner systematic with the procedure. To check this, we turned the 52100 blocks over to Dr. Allan Melmed and Mr. James Carroll, NBS Corrosion and Electrodeposition Section, for a measurement of the optical phase shift on reflection from the surfaces. Although these tests indicated (in green light) that there was a $1^{\circ}$ difference in phase shift systematic with the cleaning procedure, the magnitude of the difference would not account for the measured diametric differences. (See section $8 \mathrm{a}$ ).

Inasmuch as neither of the above two tests provided any indication why, on the average, vapor degreased balls appeared about $0.037 \mathrm{\mu m}$ larger than the same balls after chemical cleaning, we consulted a metrologist whose judgment we trust, $\mathrm{Mr}$. Arthur Strang, NBS. He told us that when there are unexplained statistically significant differences between two groups of exterior measurements on the same object, the rule-of-thumb is to accept the smaller value. This is based upon the assumption that 
the larger value includes some foreign surface layer or $f i 1 m$. We shall accept this philosophy, pending future work, and subtract $0.0347 \mu \mathrm{m}$ from the reported value of each of the six balls. This amounts to a volumetric decrease of about $0.00022 \mathrm{~cm}^{3}$ or $1.6 \mathrm{ppm}$. (See table 2.)

\section{Oxide Growth}

We have been experimenting with silicon crystals since the early 1950's at which time we were using the Cartesian Diver [10] to measure the density differences between small (2 or 3 gram) specimens. We were aware of the possibility of a growth of oxide altering the densities of the samples so we subjected them to a treatment which was believed to accelerate the oxide growth prior to our density tests. This treatment, suggested by R.D. Deslattes, NBS Quantum Metrology Section, consisted of boiling the crystals in water for several hours.

Although we did not know the thickness of the oxide growth obtained during the treatment, we felt that it amounted to several years' normal growth which put us far out on the exponential curve of Archer [11] which estimates an increase in thickness of about $6.8 \mathrm{~A}$ per decade. The crystals used in this experiment were given this treatment but, in addition, they were steamed in our vapor degreaser for about a day.

We were fortunate in that one of the technical referees to whom the NBS Editorial Board submitted our manuscript, Mr. Clayton Teague, NBS Optics and Micrometrology Section, had some familiarity with the growth of oxide on silicon surfaces. His comments to us, appendix 3, indicated that under the worst circumstances and with no pretreatment of the surfaces, the crystal couid change in density by about $1 / 10 \mathrm{ppm}$ during the first year. In the absence of definitive data on the form or character of the oxide, it was impossible to state with assurance whether the density change would be positive or negative. Without information on the adequacy of our pretreatment, we included Teague's remarks wi thout comment in our manuscript.

We have recently looked into this matter in some detail. We described the pretreatment process to George Liberman, NBS Semiconductor Characterization Section, who estimated that our process "probably" added an oxide film between 50 and $100 \AA$ thick. By Archer's equation, it would appear that 20 years would be required to grow such a film, with an additional $6.8 \AA$ forming in the next decade (200 years). We performed the following tests: 
1. We made six determinations on the density of our crysta 1, X5, two based upon each of our other three crystals. These six measurements gave us

\begin{tabular}{rr}
2.329 & $1198 \mathrm{~g} / \mathrm{cm}^{3}$ \\
87 & $"$ \\
92 & $"$ \\
86 & $"$ \\
80 & $"$ \\
76 & $"$ \\
\hline $2.329 \quad 1186$ & $\mathrm{~g} / \mathrm{cm}^{3}$
\end{tabular}

2. We etched $X 5$ in HF which presumably removed the existing oxide growth. This resulted in reducing the mass of X5 from 199.932644 grams to 199.426601 grams.

3. We again made six determinations on $\times 5$ using $X 2, \times 3$ and $X 4$ as standards which gave us density values of

$\begin{array}{rrr}2.329 & 1175 \mathrm{grams} / \mathrm{cm}^{3} \\ 87 & " \\ 71 & " \\ 91 & " \\ 86 & " \\ & 82 & " 1 \\ & \\ \text { AVERAGE } 2.329 & 1182 \mathrm{grams} / \mathrm{cm}^{3}\end{array}$

These twelve measurements on the density of $\times 5$ are plotted in figure 3 , and it is obvious that if there was a change in $\times 5$ 's density, it was at a level far below our ability to observe it with any degree of reliability.

In light of the above comments, we believe that the pretreatment applied to our four silicon crystals is quite adequate. Dr. Liberman has suggested that future crystals be treated in superheated steam which permits an accurate prediction of the thickness of the oxide layer to be grown. We are presently preparing a pair of these crystals for BIPM, and this treatment will be given to them. 


\section{Recalculation of Crystal Densities}

A. Numerical Errors

We made four numerical mistakes in the fringe fractions associated with the interferometric measurements of the diameter of Ball A:

\begin{tabular}{|c|c|c|c|c|}
\hline Date & Test & Sense & $\begin{array}{c}\begin{array}{c}\text { Value } \\
\text { Reported }\end{array} \\
\end{array}$ & $\begin{array}{c}\text { Correct } \\
\text { Value }\end{array}$ \\
\hline $2-17-72$ & 6 & Right & 0.668 & 0.678 \\
\hline $2-17-72$ & 9 & Left & 0.395 & 0.335 \\
\hline $3-6-72$ & 3 & Right & 0.194 & 0.320 \\
\hline $3-6-72$ & 8 & Left & 0.036 & 0.090 \\
\hline
\end{tabular}

The correction of these errors changes the average diameter of Ball $\mathrm{A}$, in the caption to table $4 \mathrm{a}$ in the final report, from $6.35001116 \mathrm{~cm}$ to $6.35001103 \mathrm{~cm}$ and the average volume from $134.067062 \mathrm{~cm}^{3}$ to $134.067052 \mathrm{~cm}^{3}$. This changes our assumption of the sum of the volumes of balls $A$ and $B$ (used in the least squares solution shown in table 6 of the final report) from $268.133950 \mathrm{~cm}^{3}$ to $268.133940 \mathrm{~cm}^{3}$. This represents a change of $(-) 0.000010 \mathrm{~cm}^{3}$ or $(-)$ $0.037 \mathrm{ppm}$ in the assumed volume of the standards in Determination A-B. We must make proportional reduction in the least squares estimate of the volumes of the four crystals obtained in this determination. Since the final overall estimate of the crystal volumes was the average of three determinations and no errors were found in determinations $C-D$ and $E-F$, the required reduction of our final overall estimate of the volumes of the four crystals need be reduced by only $1 / 3$ of the -0.037 ppm mentioned above or (-) $0.012 \mathrm{ppm}$.

B. Recalculation of Etalon Length.

As pointed out in section 4 on Fringe Pattern Analysis, the preferred method of fringe pattern data reduction results in reducing the data spread by about $1 / 2$ but it also results in a reduction of $(-)$ $0.0048 \mu \mathrm{m}$ in our average etalon length. This results in a reduction of all measured values of all ball diameters by an equal amount. For an average ball diameter of $63500 \mu \mathrm{m}$, this is (-) $0.076 \mathrm{ppm}$ in diameter or (-) $0.227 \mathrm{ppm}$ in the volumes of the balls AND ALSO of all four crystals. 
C. Change in data associated with ball cleaning.

In table 2 it is seen that the measured diameter of balls $A$ and $B$ were smaller by an average of $0.0347 \mu \mathrm{m}$ when cleaned chemically than when by vapor degreasing. The values given in our final report were based upon vapor degreased surfaces. For the reason given in section 5 we now believe that we should have chemically cleaned the ball surfaces. Accordingly, we shall apply a correction of $(-)$ $0.0347 \mathrm{Lm}$ to all measured diameters. This amounts to a diametric reduction of the balls of $0.546 \mathrm{ppm}$, or a volumetric reduction of the balls AND THE CRYSTALS of $1.639 \mathrm{ppm}$.

D. The total correction to crystal densities.

The total correction to crystal volumes is the sum of

$$
\begin{array}{rr}
\text { numerical correction } & -0.012 \mathrm{ppm} \\
\text { etalon length change } & -0.227 \mathrm{ppm} \\
\text { cleaning correction } & -1.639 \mathrm{ppm} \\
\text { total } & -1.878 \mathrm{ppm}
\end{array}
$$

We assume that a reduction of $1.878 \mathrm{ppm}$ in the

\begin{tabular}{|c|c|c|}
\hline Crystal & $\begin{array}{c}\text { Previously Reported } \\
\text { Value } \\
\end{array}$ & $\begin{array}{l}\text { New Accepted } \\
\text { Value } \\
\end{array}$ \\
\hline$\times 2$ & $2.3291245 \mathrm{~g} / \mathrm{cm}^{3}$ & $2.3291289 \mathrm{~g} / \mathrm{cm}^{3}$ \\
\hline$x 3$ & 2.3291209 & 2.3291253 \\
\hline$\times 4$ & 2.3291184 & $2.329 \quad 1228$ \\
\hline$\times 5$ & $2.329 \quad 1182$ & 2.3291226 \\
\hline
\end{tabular}
volumes of the four crystals results in an equal increase in their densities. The recalculated values of the crystal densities are given below.

8. Future Work

We are now in the realm of speculation. There are at least two laboratory arts which, when improved, will permit us to improve the values of crystal densities by mere recalculation (i.e. without additional measurement effort on our part): 
a. The phase shift occurring in the interferometer illumination when it is reflected from the surfaces of the 52100 steel balls. We assumed this to be about $202^{\circ}\left(180^{\circ}+22^{\circ}\right)$ in our published report. To the best of our knowledge, this has not been measured directly in light of $6328 \AA$. R.D. Deslattes feels that this is a major source of error. We have requested the appropriate group at NBS to make such a measurement under conditions of both vapor degreased and chemically cleaned 52100 steel surfaces. This wi 11 be done in the foreseable future.

b. An improved value of air density based upon an improved algorithm involving temperature, barometric pressure and relative humidity, all of which were measured in the course of crystal weighings. This work is being actively pursued in the Mass and Volume Section. 


\section{REFERENCES}

[1] Saunders, J.B. Sr., Ball and Cylinder Interferometer, J. Res. Nat. Bur. Stand. (U.S.), 76C (Eng. and Instr.), Nos. 1 and 2, (Jan.-June 1972).

[2] Johnson, D.P., Geometrical Considerations in the Measurement of the Volume of an Approximate Sphere, J. Res. Nat. Bur. Stand. (U.S.), 78A, No. 1, (Jan.-Feb. 1974).

[3] Bowman, H.A., Schoonover, R.M., and Carroll, C.L., A Density Scale Based on Solid Objects, J. Res. Nat. Bur. Stand. (U.S.), 78A, No. 1, (Jan.-Feb. 1974).

[4] Bowman, H.A., Schoonover, R.M., and Carroll, C.L., The Utilization of Solid Objects as Reference Standards in Density Measurements, Metrologia 10, 117-121 (1974) (Springer-Verlag, 1974).

[5] Englehard, E., Precise Interferometric Measurement of Gage Blocks, Nat. Bur. Stand. (U.S.), Circ. 581, p. 13, (1957).

[6] Bennett, J.M., Precise Method for Measuring the Absolute Phase Change on Reflection, Jour. Opt. Soc. Amer. 54, No. 5, p. 612 (May 1961).

[7] Candler, C., Modern Interferometers, Hilger and Watts, Ltd., (1951).

[8] Strang, A.G., Surface Characteristics of Gage Blocks, Nat. Bur. Stand. (U.S.), Circ. 581, p. 87, (1957).

[9] Edlen, B., The Refractive Index of Air, Metrologia, Vol. 2, No. 2 (1966).

[10] Bowman, H.A. and Schoonover, R.M., Cartesian Diver as a Density Comparator, J. Res. Nat. Bur. Stand. (U.S.), 69C, No. 3, (JuTy-Sept. 1965).

[11] Archer, R.J., Optical Measurements of Film Growth on Silicon and Germanium Surfaces in Room Air, Jour. of the Electrochemical Society, (0ct. 1957).

[12] Palmberg, P.W., Auger Electron Spectroscopy, Proc. Int'1. Conf. on Electron Spectroscody, Edited by D. A. Shirley, North Hol and, (1972). 


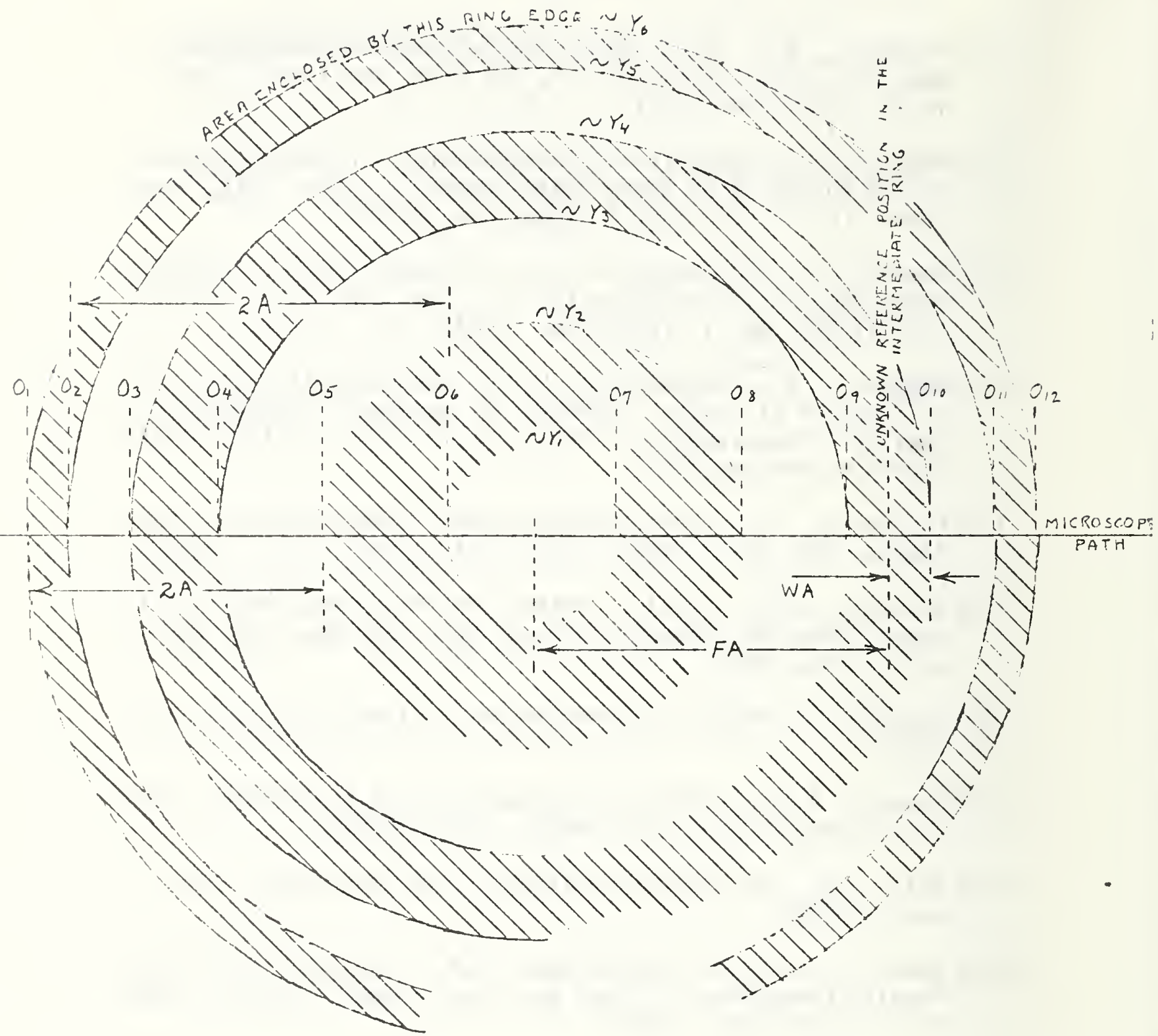

FIGURE I. THIS SIRETCH OF AN INTERFEROMETRIC RING SYSTEM INDICATES THE DIMENSIONS AND MEASUREMENTS SIGNIFICANT TO THE D.P. JOHNSON TECHNIGUE FOR CALCULATION OF THE FRINGE FRACTION INDICATED BY THE PATTERN. 
BALL DIAMETER

IN INCHES

$2,500005-$

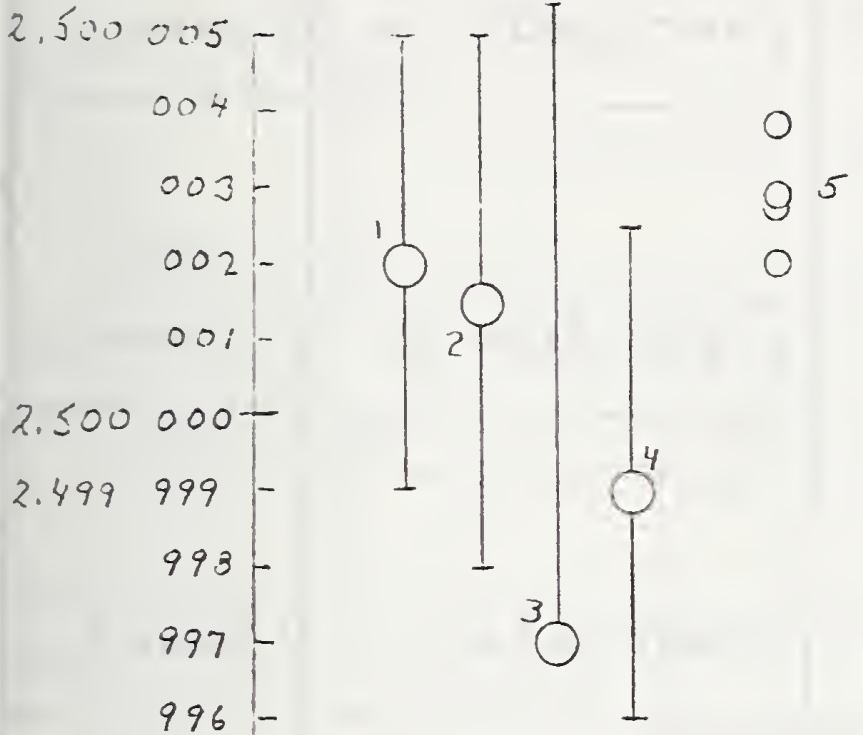

BALL "A"



$995-$

994

FIGURE 2. THIS FIGURE INDICATES THE VARIOUS MEASUREMENTS MADE OH BALLS A AND B. THE NUMBERS ASIDE THE DATA POINTS INDICATE THE SOURCE OF DATA AS FOLLOWS: ', THE MANUFACTURER'S ESTIMATE; 2 AND 4 , THE FIRST AND SECOND ESTIMATES, RESPECTIVELY, OF OUIR DIMENSIONAL METROLOGY LABORATORY; 3 , THE MINIMUM DIAMETRIC ESTIMATE OF OUR GAGE BLOCK LABORATORY; 5 , INTERFEROMETRIC MEASUREMENTS FOLLOWING CHEMICAL CLEANING.



FICURE 3. MEASURED VALUES OF THE DENS:TY OF SILICON CRYSTAL DESIGNATED XS BEFOIRE AND AFTER ETCHINE. FROM THIS DITA WE CONCLUOE THAT OUR MEASUREMENTS ARE INADEQUHTELY PRELISE TO JEFINE ANY POSSIBLE DENSITY CHANGE. 


\begin{tabular}{|c|c|c|c|c|c|c|}
\hline \multirow{2}{*}{ TEST } & \multirow{2}{*}{\multicolumn{2}{|c|}{ DIRECTION }} & \multicolumn{2}{|c|}{ SALCULATKO FRACTION } & \multirow{2}{*}{$\begin{array}{l}\text { NEW ETALON LENGTH } \\
\text { AT TEST TEMP }\end{array}$} & \multirow{2}{*}{$\begin{array}{l}\text { NEW LENGTH } \\
\text { MINUS OLD }\end{array}$} \\
\hline & & & $0<0$ & NEW & & \\
\hline \multirow[t]{2}{*}{$E T-1$} & \multicolumn{2}{|l|}{$\begin{array}{l}L \rightarrow R \\
R \rightarrow L\end{array}$} & $\begin{array}{l}.679 \\
.701\end{array}$ & & \multirow{2}{*}{$67471.6054 \mu$} & \multirow[b]{2}{*}{$k .0046 \mu$} \\
\hline & $=\cdots$ & $\begin{array}{l}\text { AVG } \\
\text { RANGE }\end{array}$ & $\begin{array}{l}.690 \\
.022\end{array}$ & $\begin{array}{l}.674 \\
.015\end{array}$ & & \\
\hline \multirow[t]{2}{*}{$E T-2$} & \multirow[t]{2}{*}{$\begin{array}{l}L \rightarrow R \\
R \rightarrow L \\
L \rightarrow R \\
R \rightarrow L\end{array}$} & I & $\begin{array}{l}.561 \\
.560 \\
.541 \\
.551 \\
\end{array}$ & $\begin{array}{r}.549 \\
.540 \\
.538 \\
.539 \\
\end{array}$ & \multirow{2}{*}{$67471.5605 \mu$} & \multirow[b]{2}{*}{$(-) .0035 \mu$} \\
\hline & & $\begin{array}{l}\text { AVC } \\
\text { RANGE }\end{array}$ & $\begin{array}{l}.553 \\
.020 \\
\end{array}$ & $\begin{array}{l}.541 \\
.011 \\
\end{array}$ & & \\
\hline \multirow[t]{2}{*}{$E T-3$} & \multirow[t]{2}{*}{$\begin{array}{l}L \rightarrow R \\
R \rightarrow L \\
L \rightarrow R \\
R \rightarrow L\end{array}$} & & $\begin{array}{l}.366 \\
.343 \\
.341 \\
.338 \\
\end{array}$ & $\begin{array}{l}.335 \\
.327 \\
.314 \\
.327 \\
\end{array}$ & \multirow[b]{2}{*}{$67471.6026 \mu$} & \multirow{2}{*}{$(-) .0064 \mu$} \\
\hline & & $\begin{array}{l}\text { AVC } \\
\text { RANGE }\end{array}$ & $\begin{array}{l}.347 \\
.028 \\
\end{array}$ & .3 & & \\
\hline \multirow[t]{2}{*}{$\begin{array}{c}E \boldsymbol{T}-\boldsymbol{4} \\
\vdots \\
\vdots\end{array}$} & \multirow[t]{2}{*}{$\begin{array}{l}L \rightarrow R \\
R \rightarrow L \\
L \rightarrow R \\
R \rightarrow L\end{array}$} & $\vdots \ldots$ & $\begin{array}{l}.292 \\
.307 \\
.296 \\
.280\end{array}$ & $\begin{array}{l}.275 \\
.286 \\
.278 \\
.278 \\
\end{array}$ & \multirow{2}{*}{$\begin{array}{c}1 \\
6 \\
67471.6019 \mu\end{array}$} & \multirow{2}{*}{$\begin{array}{r}\vdots \\
\vdots \\
(-) .0041 \mu \\
\end{array}$} \\
\hline & & $\begin{array}{l}\text { AVC } \\
\text { RANGE }\end{array}$ & $\begin{array}{l}.294 \\
.027 \\
\end{array}$ & $\begin{array}{l}.279 \\
.010 \\
\end{array}$ & & \\
\hline \multirow[t]{2}{*}{$E T-5$} & \multirow[t]{2}{*}{$\begin{array}{l}L \rightarrow R \\
R \rightarrow L \\
L \rightarrow R \\
R \rightarrow L\end{array}$} & $\begin{array}{c}1 \ldots+1 \\
\cdots \\
1 \\
1\end{array}$ & $\begin{array}{l}.216 \\
.185 \\
.202 \\
.201\end{array}$ & $\begin{array}{l}.183 \\
.177 \\
.178 \\
.183 \\
\end{array}$ & \multirow{2}{*}{$\begin{array}{c}1 \\
67471.6861 \\
\vdots \\
6\end{array}$} & \multirow{2}{*}{$(\rightarrow) .0059 \mu$} \\
\hline & & $\begin{array}{l}\text { AVG } \\
\text { RANCE }\end{array}$ & $\begin{array}{l}.201 \\
.031 \\
\end{array}$ & $\begin{array}{l}.180 \\
.006 \\
\end{array}$ & & \\
\hline \multirow[t]{2}{*}{$E T-6$} & \multirow[t]{2}{*}{$\begin{array}{l}L \rightarrow R \\
R \rightarrow L \\
L \rightarrow R \\
R \rightarrow L\end{array}$} & & $\begin{array}{l}.076 \\
.078 \\
.090 \\
.074 \\
\end{array}$ & $\begin{array}{l}.060 \\
.067 \\
.073 \\
.058\end{array}$ & \multirow{2}{*}{$67471.7005 \mu$} & \multirow{2}{*}{$\mid \begin{array}{c}\vdots \\
(-) .0045 \mu\end{array}$} \\
\hline & & $\begin{array}{l}\text { AVC } \\
\text { RANGE }\end{array}$ & $\begin{array}{l}.079 \\
.016\end{array}$ & $\begin{array}{l}.064 \\
.015\end{array}$ & & \\
\hline \multicolumn{5}{|l|}{ (i) } & \multirow{2}{*}{\multicolumn{2}{|c|}{ AVERACE DIFFERENCE $=(-) .0048 \mu$}} \\
\hline AVER & & RANGE = & .024 & .013 & & \\
\hline
\end{tabular}

TABLE 1. COLUMNS 3 AND 4 SHOW THE IMPROVEMENT IN THE REPRODUCIBILITY OF CALCULATEO VALUES OF FRINGE FRACTIONS WHEN THE TAREE-RINC FORMAT DESCRIBEO IN SECTION IV IS EMPLOYED. 
Date: June 14,1972

To: Horace Bowman

Yass, Length and Volune Section (232.09)

Fron: Dannis A. Siryt

Dinensional Techology Section (232.12)

Subject: Veasurement of five spheres

The arithnetic averace surface roughness ( $A$ ) has becn moasured, for five spileres, using a Talysurf stylus instmment fith a curved surface latum attachment. Sone relevant parameters arc: sphere diameters of appro:imately 2.5 inches; a stylus diareter of 200 microinches; a stylus pressuro of 5 n miligrans; a meter vavelength cutoff of .010 inch; a meter gain of 20,000; a full scale reading of 10 microinches; a reading precision of + .I microinch; and an inherent noise level probably of less than . 5 microinches.

Stx pairs of readings were taken at roughiy equaliy spaced points on tha surface of the spheres. The averages of the pairs of readings appear in Table I; the mean $A$ value and Pis deviations fron the mean his value for each sphoto are given in Table II.

A sample profile trace is appended. It should he notad that the curvature of the trace corresponds to the diffurence between (1) the surface of the sphers and (2) the curve generated by the datun attachent of the device; therefore, the trace curvature mav not he interpreted in terms of tha sphere surface alone.

Tahle I. Arithmetic averaze surface roughness readings. (nicroinches) $\div$

\begin{tabular}{|c|c|c|c|c|}
\hline$S I$ & 52 & 53 & 55 & $? 1$ \\
\hline 1.55 & 1.35 & $1.7 n$ & 1.25 & 2.25 \\
\hline $1.7 n$ & $1.3^{n}$ & 1.75 & 1.20 & 1.05 \\
\hline 3.79 & 1.45 & 1.55 & 1.25 & 2.35 \\
\hline $1.5 ?$ & 1. $3 n$ & $1.7 ?$ & 1.50 & 2. 3n? \\
\hline $1.6 n$ & 1.25 & 7.45 & 1.55 & $\therefore .75$ \\
\hline 1.35 & 1.25 & $1.7 n$ & 1.45 & 1. $n n$ \\
\hline
\end{tabular}

- Miv rne recimai place is significant. 
Table II. Mlean AN readings for each sphere (microinches) $*$

$\left.\begin{array}{|c|c|c|}\hline \text { s1 } & 1.32 \pm .08 \\ \text { s2 } & 1.57 \pm .13 \\ \text { s3 } & 1.64 \pm .11 \\ \text { s5 } & 1.38 \pm .18 \\ \text { Q1 } & 2.13 \pm .19\end{array}\right]$


. 


\section{Matt Ono \\ Ralph Gorden, Jr. \\ Surface Processes and Catalysis Section \\ Institute for Materials Research \\ National Bureau of Standards \\ Washington, D.C. 20234}

Two gauge blocks received from Dr. H. Bowman, IBS, were analyzed in an attempt to determine whether some surface deposit may be responsible for dimensional differences observed by optical measurements. One block was chemically cleaned and the other vapor cleaned. The samples were inscribed J66IA (0.1001 in.) and J199A (0.1004 in.), respectively.

An Auger spectrometer was used to analyze the surface of the samples. A sputter ion gun was then used for layer by layer removal of the surface using $1 \mathrm{kV}$ argon ions produced in $4 \times 10^{-5}$ Torr pressure of argon gas. An Auger analysis was performed intermittently during sputtering. The time of bombardment (therefore the thickness of layer removed in each interval) did not coincide in every analysis for both gauge blocks, but the cumulative sputtering loss should be nearly the same in both analyses.

SURFACE ANALYSIS BEFORE' ION BOMBARDMENT

The following chart tabulates results from the initial surface examination:

\begin{tabular}{cccc} 
ELEMENT & $\begin{array}{c}\text { ELECTRON } \\
\text { ENERGY }\end{array}$ & $\begin{array}{c}\text { SAMPLE } \\
\text { J199A(v.cl.) }\end{array}$ & $\begin{array}{c}\text { SAMPLE } \\
\text { J661A(c.cl.) }\end{array}$ \\
\hline $\mathrm{eV}$ & 273 & $\frac{\begin{array}{c}\text { Auger peak height } \\
\text { (arbitrary units) }\end{array}}{4.02}$ & $\begin{array}{c}\text { Auger peak height } \\
\text { (arbitrary units) }\end{array}$ \\
$\mathrm{O}$ & 510 & 6.35 & 1.80 \\
$\mathrm{Zn}$ & 994 & .03 & 5.25 \\
$\mathrm{~S}$ & 152 & .19 & .07 \\
$\mathrm{~B} / \mathrm{Cl}$ & $179 / 181$ & .51 & .28 \\
$\mathrm{Na}$ & 990 & $?$ & $? .42$ \\
$\mathrm{Fe}$ & 598 & 1.70 & \\
& 651 & &
\end{tabular}


At the very surface, carbon is much more abundant on the vapor cleaned (v.cl.), Sample J199A. For zinc, the signal approaches noise level especially in sample J199A and may not be distinguished from sodium which appears in the same vicinity of the spectrum. From other experiments, zinc is more positively identified on sample J66lA, although it may contain a trace of sodium. All other elements are of similar concentration on both blocks.

The secondary electron spectrum below $60 \mathrm{eV}$ is normal in sample J199A, but significantly different in J66IA. This may signify some abnormal surface phenomenon (see Spectra 10 and 11).

DEPTH PROFILING

The results are illustrated in Figures 1, 2, and 3 for carbon, oxygen, and iron. In Figure 3, the Auger yields of carbon and oxygen are normalized to that of iron. There is little difference in the depth profiles of the two gauge blocks. Oxygen increases to a maximum at about five minutes of ion bombardment, while carbon goes through a minimum at that time then increases to an apparently constant value after fifteen minutes.

Iron increases steadily showing an inflection, when oxygen is near its maximum, then continues to a fairly constant value after about fifteen minutes sputtering.

Zinc and/or sodium is removed by sputtering for about 30 seconds in sample J199A and for less by sputtering than 2 minutes on sample J66IA.

A trace of sulfur is present on both blocks. Trace amounts of Mo, Cl, and/or B may be present but could not be unambiguously identified, since the argon lines appear in this same energy range. INTERPRETATION OF RESULTS

The rate of $\left(\mathrm{Ar}^{+}\right)$ion sputtering for pure aluminum layers has been

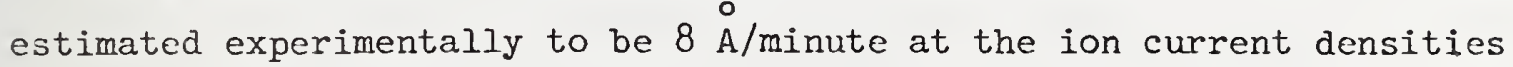
employed in this work. This sputter rate may be used as a crude approximation in interpretation of our sputtering profile data.

The sputter profiles obtained in this study (Figs. 1 and 2) indicate that in both cases there is a thin carbon impurity layer (removed in about 
five minutes) overlaying a layer of iron and oxygen. These may be in the form of iron oxide since their Auger intensities increase simultaneously for about five minutes where oxygen begins to rapidly decrease and iron levels off. As this layer is removed, the clean surface of the block is exposed. This results in an increase in iron and carbon intensities until they level off (at about fifteen minutes bombardment) no doubt reflecting the composition of the bulk iron of the blocks.

The small differences in the curves of Fig. 3 may be due to interruption or differences in sputtering time between the two samples.

There is practically no difference in the surface composition of the two blocks. However, one cannot discount the possibility of some surface impurity pumping away in the ultrahigh vacuum system (at pressures of the order of $10^{-10}$ Torr and at temperature of $300 \mathrm{~K}$ ).

The differences observed between the two samples by optical measurements may be related to the different secondary electron behavior observed here, or possibly to non-uniform distribution of surface contaminants. Further examination by replica electron microscope, IMA, or XPS may be desirable. 
cheserciviny cisuned

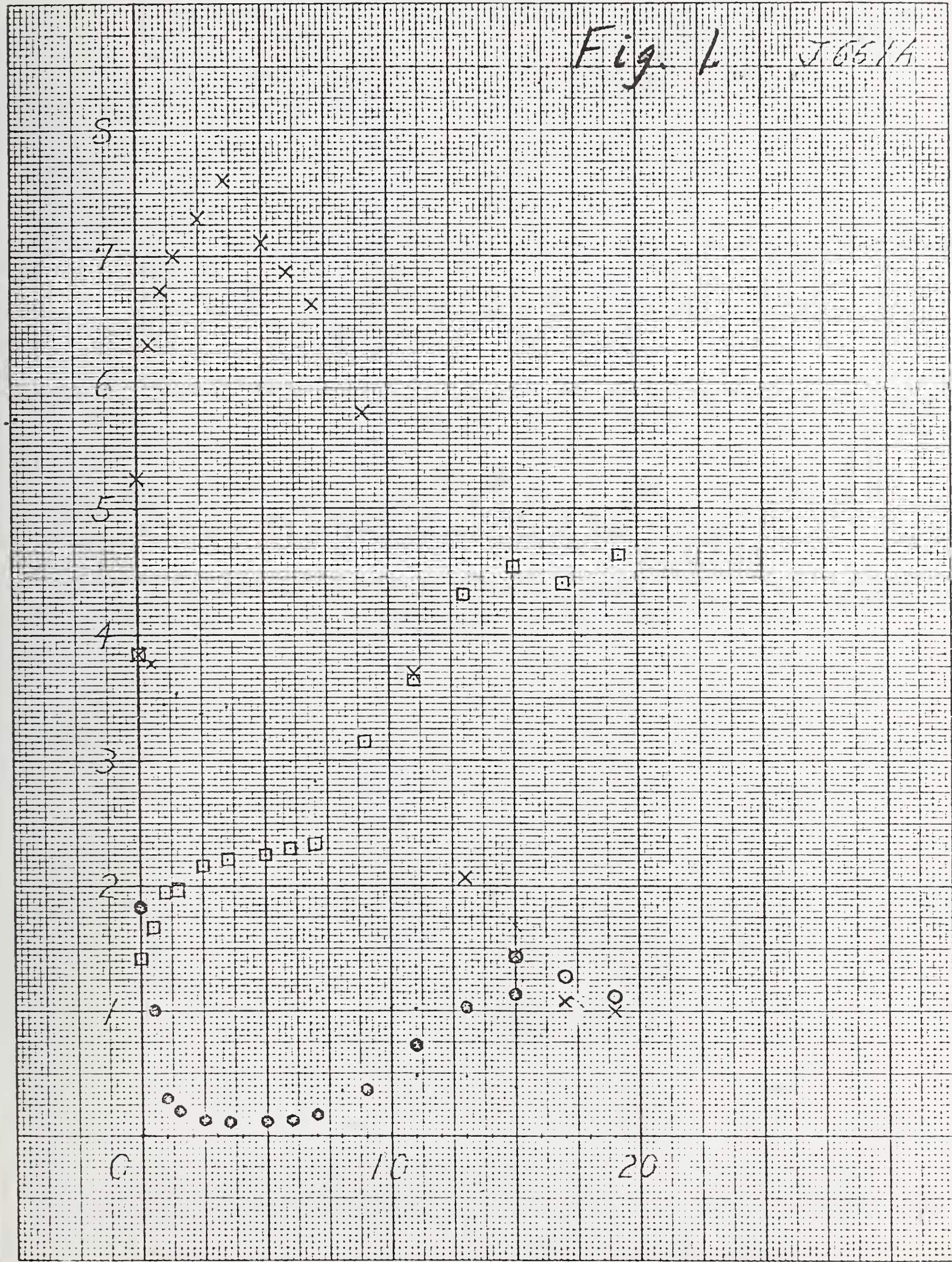


$\frac{1}{4} \sqrt{4} \times$

49680494

$7 \times$ $x=$

$=\ldots$

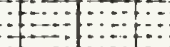

. . . . .

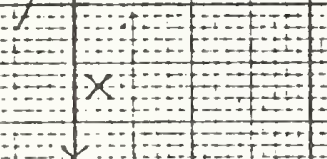

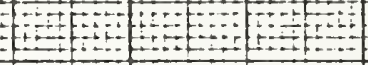

- 1

$\times 6$

$6 \pm$

$x$

$+\quad \square=$

Q E

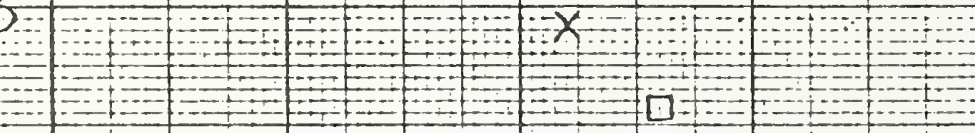

40

$+1$

$+1=$



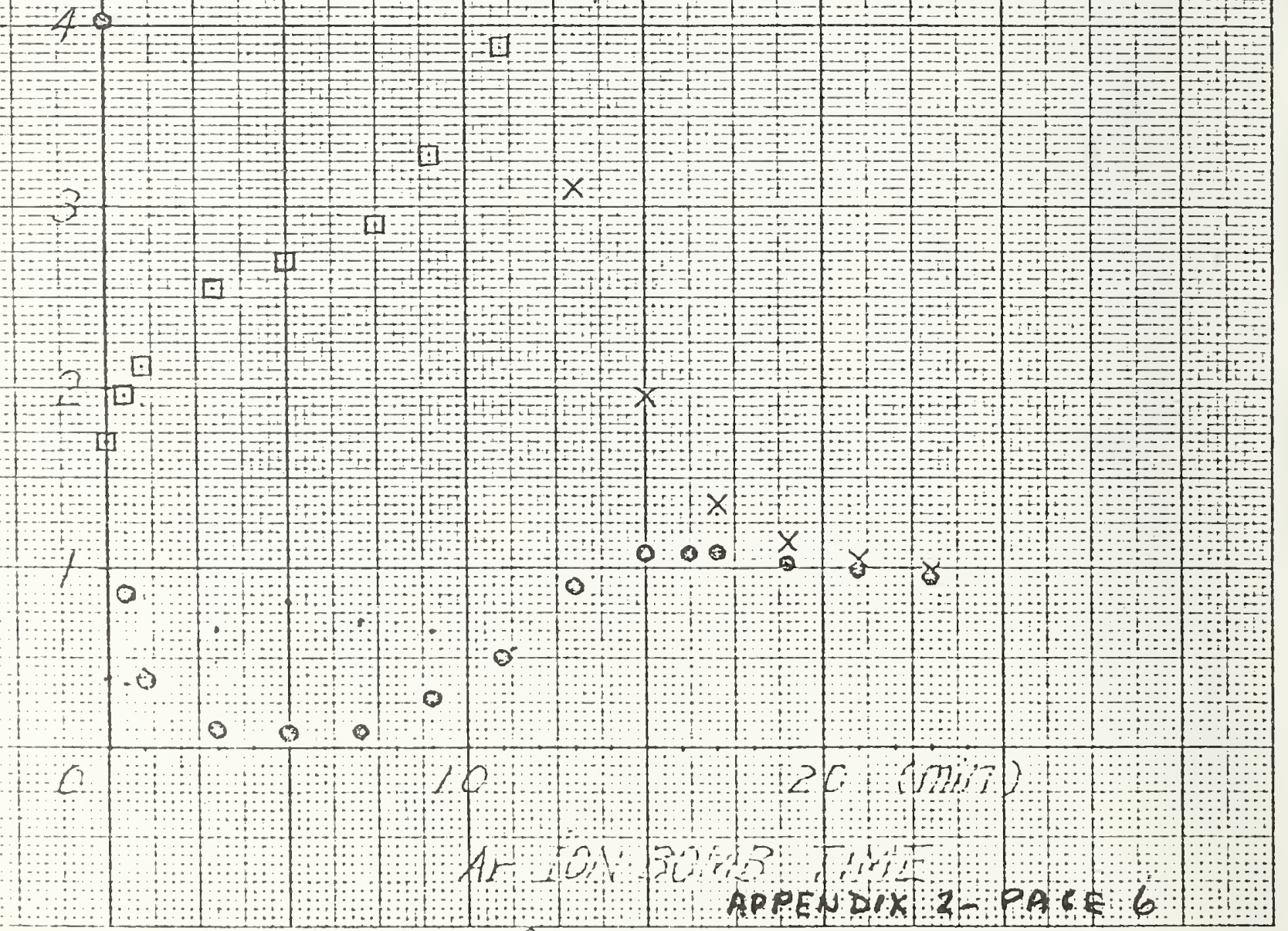

.....

$1 \times$

Imin of order $8 A$ if al : do ' krow for fe or teO. 







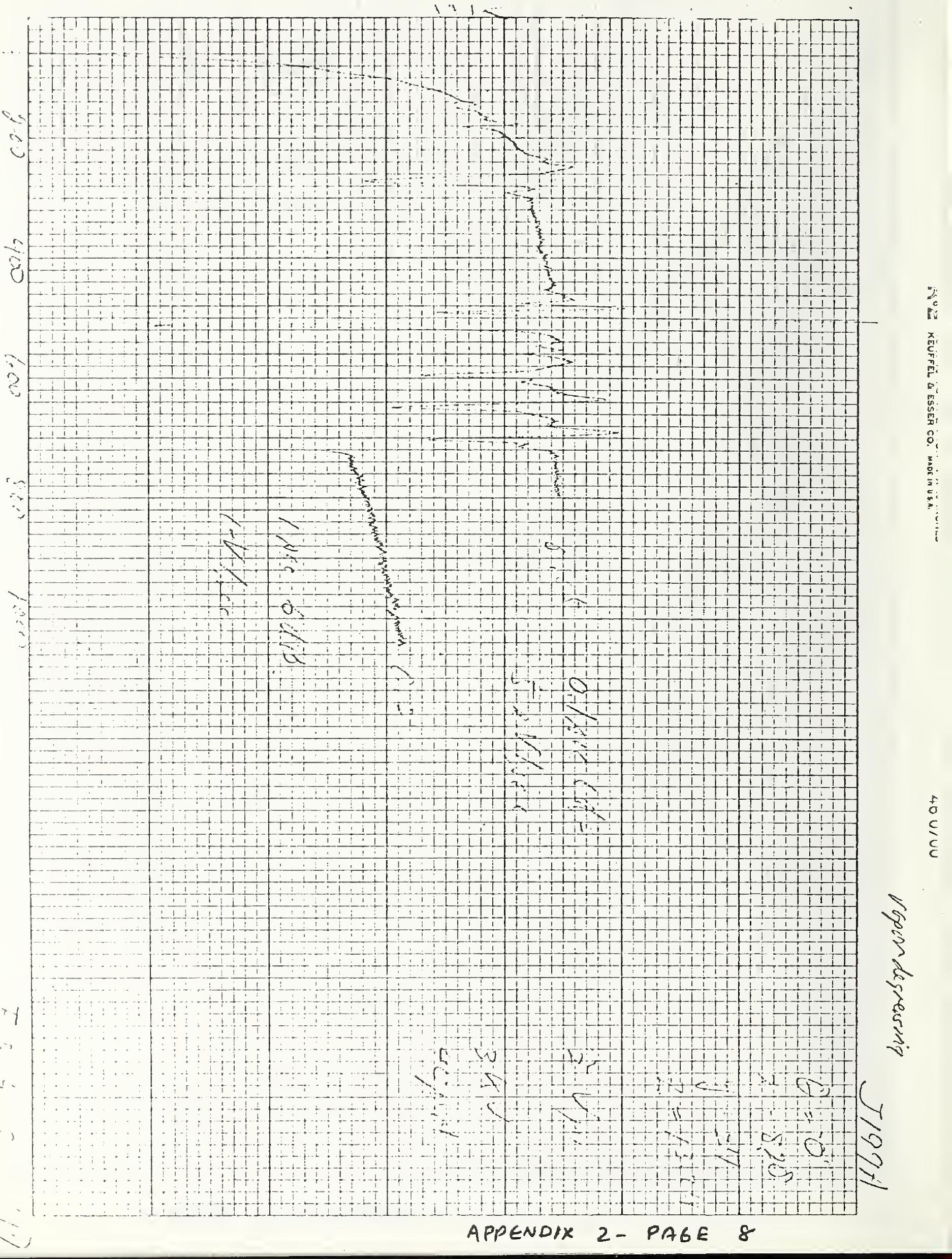


$\frac{m}{m}$

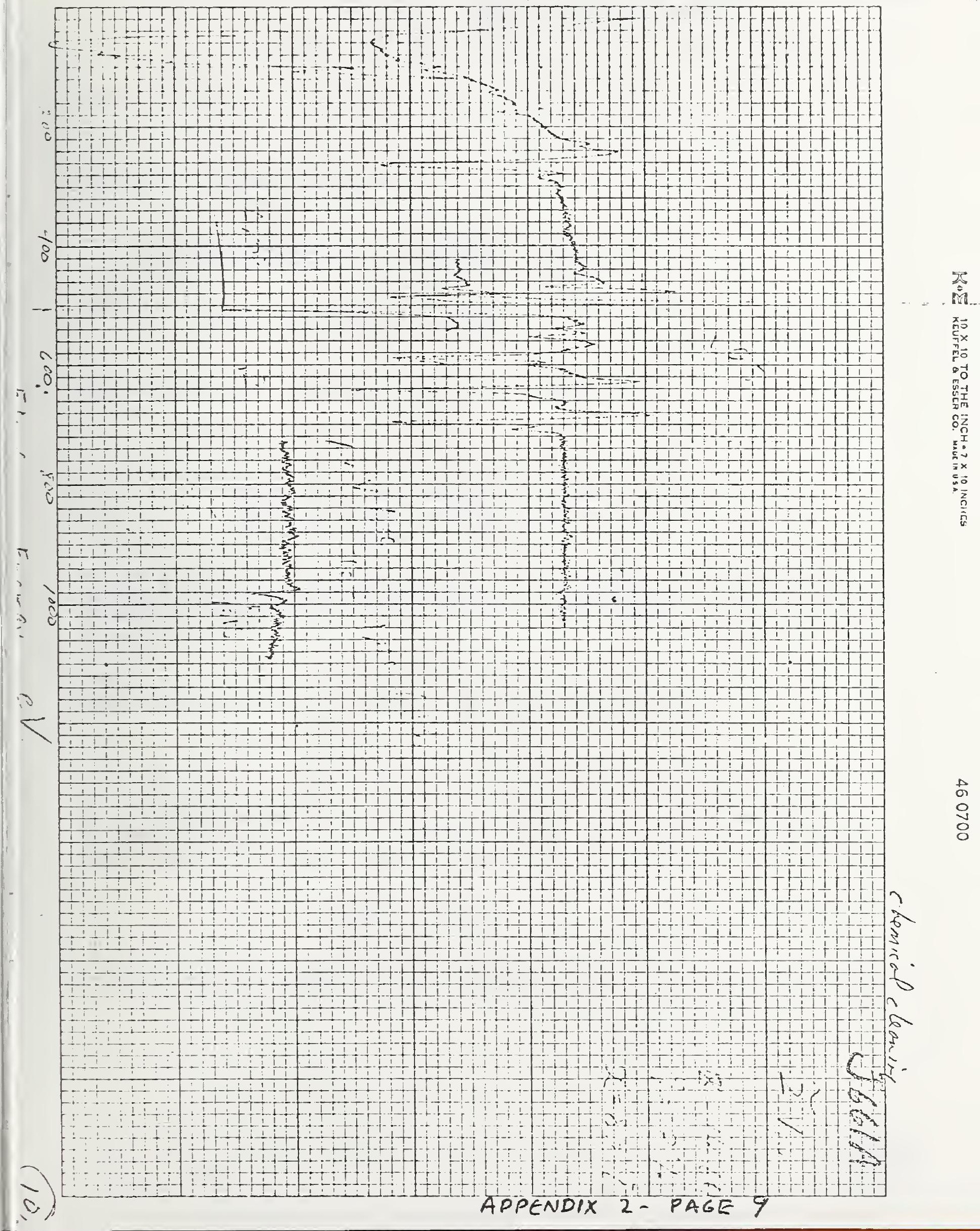



May 30,1973

MEMORANDUM FOR Horace A. Bowman Mass and Volume Section

From: E. Clayton Teague optics and Micrometrology Section

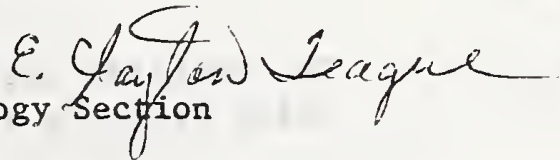

Subject: Some consideration of the effects of oxide growth on the density of silicon specimens.

The bases for these considerations is the following.

$$
\begin{aligned}
& \rho \text { (silicon) } \equiv \rho_{\mathrm{Si}}=2.33 \mathrm{~g} / \mathrm{cm}^{3} \\
& \rho \text { (silicon oxide) } \equiv \rho_{\mathrm{SiO}}=2.0 \text { to } 2.66 \mathrm{~g} / \mathrm{cm}^{3} \\
& \text { The specific value depends on the oxide growth conditions } \\
& \text { and the resultant crystallographic form of the oxide, see } \\
& \text { Silicon Semiconductor } \underline{\text { Data } \text { Edited by Wolf. }}
\end{aligned}
$$

At room temperature, the change in oxide thickness after an initial oxidation of several hours is approximately $5 \mathrm{~nm}$ for a 2 year oxidation. This value is an estimate obtained from A. T. Fromhold, Jr., at Auburn University in private communication.

Assuming no silicon is lost during the oxidation process, the silicon specimen's change in mass with oxidation, dm, may be expressed as:

$$
\mathrm{dm}=\mathrm{a} \rho_{\mathrm{SiO}} \mathrm{dv} \mathrm{v}_{\mathrm{O}}
$$

where $d v_{0}$ is the change in the oxide's volume and a is a constant determined by the oxide's molecular form. If the molecular form is $\mathrm{SiO}_{2}$ then a is approximately 0.5 . If the net specimen density and volume is $\rho$ and $v$ repectively then the fractional change in density is:

$$
\frac{d \rho}{\rho}=\frac{{ }^{a} \rho_{S i 0} d v_{o}}{\rho_{S i} v}-\frac{d v_{s}}{v},
$$

where $d v_{s}$ is the specimen's change in volume. 
With the data from Wolf $\rho_{\mathrm{SiO}} / \rho_{\mathrm{S} 1}$ is approximately 1 . Therefore:

$$
\frac{d \rho}{\rho}=a \frac{d v_{o}}{v}-\frac{d v_{s}}{v} .
$$

In the two extreme cases:

$$
\begin{aligned}
& d v_{s}=d v_{0} ; \quad \text { The specimen surface is displaced by the } \\
& \text { oxide growth's thickness, }
\end{aligned}
$$

and

$$
d v_{s} \quad<d v_{0}
$$

one obtains the result:

$$
\left|\frac{d \rho}{\rho}\right|=|1-a| \frac{d v_{o}}{v}
$$

as an upper bound on the magnitude of the density change. For your cylindrical density specimens, approximately 1 inch by 2 inches in diameter, this value is:

$$
\left|\frac{\mathrm{d} \rho}{\rho}\right|=2|1-\mathrm{a}|\left(\frac{1}{\mathrm{~h}}+\frac{1}{\mathrm{r}}\right) \Delta \mathrm{t},
$$

where $\mathrm{h}=$ cylinder height, $\mathrm{r}=$ cylinder radius, and $\Delta t=$ oxide thickness change. The use of Fromhold's $5 \mathrm{~nm}$ value for $\Delta t$ and an a of 0.5 (for $\mathrm{SiO}_{2}$ ) gives:

$$
\left|\frac{d p}{p}\right| \approx 4 \times 10^{-7}
$$

over a two year period.

A lower bound for the density change, other than zero, appears very difficult to estimate without going into greater detail on the molecular forms, accurate values of the oxide density, etc. 
NBS.114A (REV. 7.73 )

\begin{tabular}{|c|c|c|c|}
\hline $\begin{array}{l}\text { U.S. DEPT. OF COMM. } \\
\text { BIBLIOGRAPHIC DATA } \\
\text { SHEET }\end{array}$ & $\begin{array}{l}\text { 1. PUHBLICATION (IR RIIOOKI NO } \\
\text { NBSIR 75-768 }\end{array}$ & $\begin{array}{l}\text { 2. Ciov't Accossion } \\
\text { No. }\end{array}$ & 3. Recipient's Accessiun Nu. \\
\hline \multicolumn{3}{|l|}{ 4. TITI.F AND SUBTITLE: } & $\begin{array}{l}\text { 5. Publication [are } \\
\text { August } 1975\end{array}$ \\
\hline \multicolumn{3}{|c|}{$\begin{array}{l}\text { Reevaluation of the Densities of the } \\
\text { Four NBS Silicon Crystal Standards }\end{array}$} & 6. Performing Organifation (ods \\
\hline \multicolumn{3}{|c|}{ 7. ALTHRR.A' Bowman, R.M. Schoonover, and C.L. Carroll } & $\begin{array}{l}\text { 8. Performing Oegan. Repurt No. } \\
\text { NBSIR 75-768 } \\
\end{array}$ \\
\hline \multirow{2}{*}{\multicolumn{3}{|c|}{$\begin{array}{l}\text { 9. PERF ORMING ORGANIZATION NAME AND ADDRESS } \\
\text { NATIONAL BUREAU OF STANDARDS } \\
\text { DEPARTMENT OF COMMERCE } \\
\text { WASHINGTON, D.C. } 20234\end{array}$}} & 10. Project/Task/Work Unit No. \\
\hline & & & 11. Contract/Grant No. \\
\hline \multirow{2}{*}{\multicolumn{3}{|c|}{$\begin{array}{l}\text { 12. Sponsoring Organization Name and Complete Address (Street, City, State, ZIP) } \\
\qquad S A M E\end{array}$}} & $\begin{array}{l}\text { 13. Type of Report \& Period } \\
\text { Covered }\end{array}$ \\
\hline & & & 14. Sponsoring Agency Code \\
\hline
\end{tabular}

15. SUPPLEMENTARY NOTES

16. AlBSTRAC:T (A 200-word or less tactual summary of most sifnilicant in formation. If document includes a significant bibliography or literature survey, mention it here.)

There were a few features of our recently completed density standard experiment which were based upon ideas which, we believe, should be changed. This report lists these changes and their justification. The result is to increase the assumed values of the densities of the crystals by about $1.7 \mathrm{ppm}$. The new assumed values are

$$
\begin{aligned}
& X_{2}=2.3291289 \mathrm{~g} / \mathrm{cm}^{3} \\
& X_{3}=2.3291253 \mathrm{~g} / \mathrm{cm}^{3} \\
& X_{4}=2.3291228 \mathrm{~g} / \mathrm{cm}^{3} \\
& X_{5}=2.3291226 \mathrm{~g} / \mathrm{cm}^{3}
\end{aligned}
$$

Additionally, we now believe that the densities of the crystals are stable, and not appreciably changing due to oxidation -- a point left unresolved in our published report.

17. KEY WORDS (six to twelve entries; alphabetical order; capitalize only the first letter of the first key word unless a proper name; separated by semicolons)

Density standard; phase shift; silicon

18. AVAILABILITY Xnlimited

For Official Distribution. Do Not Release to NTIS

Order From Sup. of Doc., U.S. Government Printing Office Wa shington, D.C. 20402 , SD Cat. No. C13

$\boldsymbol{X}$ Order From National Technical Information Service (NTIS) Springfield, Virginia 22151

\begin{tabular}{|l|c|}
\hline $\begin{array}{l}\text { 19. SECURITY CLASS } \\
\text { (THIS REPURT) }\end{array}$ & 34 \\
UNCL ASSIFIED & NO. OF PAGES \\
\hline $\begin{array}{l}\text { 20. SECURITY CLASS } \\
\text { (THIS PAGE) }\end{array}$ & 22. Price \\
UNCLASSIFIED & 3.75 \\
\hline
\end{tabular}

USCOMM.DC 29042.074 





